\title{
ON THE DISTINCTION BETWEEN FRIEDRICH HEGEL'S DIALECTICS AND THE LOGIC OF CONVERSATIONAL THINKING
}

DOI: https://dx.doi.org/10.4314/ajct.v1i1.2

\author{
Submission: June 26, 2021 Acceptance: September 10, 2021 \\ Emmanuel OFUASIA \\ Department of Philosophy \\ University of Lagos \\ Email: ofuasia.emma@gmail.com \\ ORCID: https://orcid.org/0000-0002-2028-6005
}

\begin{abstract}
Following the publication of Jonathan O. Chimakonam's astounding book, Ezumezu: A System of Logic for African Philosophy and Studies, a monumental piece in the history of African philosophy and logic, which also undergirds the backbone of conversational thinking, various uncharitable misconceptions and misrepresentations have greeted the work. Of the several misrepresentations and misconceptions, the tendency to treat the logic as an African variant of Friedrich Hegel's dialectics is common. Being a three-valued logic, the tendency to perceive the third value ' $\mathrm{e}$ ' in conversational thinking as a synthesis is replete in several commentaries and criticisms. This has almost become the norm since Hegel's third value, following thesis and anti-thesis signifies a synthesis. Through the method of philosophical analysis, I argue that: (1) the logic of conversational thinking is not similar to Hegel's dialectics hence, all commentaries and criticisms in this guise exhibit the Strawman fallacy; (2) for the logic that underlies conversational thinking, synthesis is an anathema; and (3) conversational thinking places emphasis on complementarity over contradiction. Following these points, I submit that when the veil of Hegel is cast aside, a deeper appreciation for an Africa-inspired logic, which has the capacity to mediate thinking for Africa and beyond, may be discerned almost effortlessly.
\end{abstract}

Keywords: African Philosophy, Conversational Philosophy, Ezumezu Logic, Friedrich Hegel, Three-valued Logic. 


\section{Introduction}

The principal character of this disquisition is to put to rest the penchant among the critics of the logic of conversational thinking, of comparing and concluding that the Ezumezu logic system is synonymous with Hegel's dialectics. Since the publication of the principles of Ezumezu logic in 2019 as a book, it seems the greatest critics of the work have come from within Africa and Nigeria in particular. This feeling is derived from the informal, unstructured interchanges with colleagues and professors in some public universities in Nigeria. Only a handful of intellectuals such as David Martens (2019), Aribiah Attoe \& Abiola Azeez (2021), Lucky U. Ogbonnaya (2021), Emmanuel Ofuasia (2019; 2021), along with other intellectuals affiliated with the Conversational Society of Philosophy (CSP), have, after reading the work copiously, provided comments concerning how the logic system may be relevant and even improved by its author, Jonathan Chimakonam. The prejudices, which the has logic generated, have led to some misconceptions and misrepresentations which I seek to put to rest in this disquisition. It needs to be said that Chimakonam (2019) stressed over and over again, how his three-valued logic, which undergirds theory, thought and method in conversational thinking differs from Hegel's dialectics and other three-valued logic systems. Hence it is perplexing how critics continue to compare his system to Hegel's even when he already made the effort to establish that the third value, ' $\mathrm{e}$ ' in his system is not a synthesis. It is therefore a matter of urgency to move beyond mere words but to accentuate and use diagrams to showing how the two systems differ both in terms of operation and application. Unless this approach is explored, the logic will continue to be caricatured as an African version of Hegel's dialectics, which in the end vitiates any form of intellectual originality emanating from Africa.

Via the method of philosophical analysis, this research aims to disclose the main traits of Chimakonam's logic and Hegel's dialectics in order to foreground how dissimilar they are from each other. In the part which follows, Hegel's dialectics and its application in his idealism, as well as its foundation in Marx's theories, are considered. Emphasis on how a thesis encounters an 
anti-thesis to birth a synthesis, which soon evolves into a new thesis, will be explained, diagrammatically. In the second section, I uncover the main thrust of Ezumezu logic. I focus mainly on how the third value functions as I pay attention chiefly to the aspects of the logic system that I find relevant to the scope of my present concern. I provide details, via a diagram, about how the third value functions. I also uncover the departures from other three-valued logic traditions and the importance of the supplementary laws of thought that Ezumezu invokes. In the third part, I draw the distinctions between Chimakonam's third value and Hegel's dialectics/synthesis and make them as vivid as possible. The fourth part concludes this research.

\section{On Friedrich Hegel's Dialectics}

Hegel has been said to be one of the greatest philosophers that Germany has ever produced. The ideas that he unmasked influenced and continue to influence the world to this day. In this piece, however, I concern with only a minute aspect of his ideas - the principle of dialectics and how it functions. This scope in Hegel's thought is in tune with the task of this study - to disassociate the third value 'e' in Ezumezu logic from Hegel's synthesis. Before settling for Hegel's version and employment of dialectics, perhaps the first task is to offer a general overview of the meaning of dialectics.

According to Anthony Kenny (2006), there is a connection between dialectics and logic, which commands what he calls dialectical logic. Specifically, dialectical logic is a science about the most general or laws of development of nature, society as well as thought (KENNY 2006, 219). It is however instructional that dialectical logic is usually adduced to have been in vogue as far as ancient Greece, with Socrates and Plato as forerunners. However, the logic aspect of dialectics has been credited to Karl Marx and those who sympathise with his ideas. In the words of Theodore Oizermann (1971, 210), "dialectical logic was developed by the Marxists as the logic of motion and change and used to examine strong forms, as it is observed as a materialist approach to logic, drawing on the 
objective material world." It must be stated that Marx does not deny the influence of Hegel and what he took from him toward developing his system. In his words, "I openly avowed myself as a pupil of that mighty thinker, Hegel" (MARX 1906, 25). Much as Marx defends Hegel against some critics, he does not waver in the admission that Hegel was the first to present dialectics as a form of operation in a comprehensive and conscious manner (MARX 1906). In spite of this open admission, Marx does not fail to point out what he views as the misapplication of dialectics. Describing Hegel on this note, he relays, "with him [dialectics] is standing on its head. It must be turned right side up again, if you would discover the rational kernel within the mystical shell (MARX 1906, 25). The target of Marx's criticism is the application of the principle of dialectics to spirit or non-material reality, which for Hegel overrides matter.

In his work, Science of Logic, Hegel formulates and discusses the principle of dialectics. It has also been recognised that the principle of dialectics is usually the starting point of any formal discourse on Hegel (REYES 2014). It is also the case that Hegel characterises dialectic as "the dialectic of the logic that ingeniously manifested itself in natural and spiritual phenomenon and consciousness" (see BEISER 1993, 131). This principle, for Hegel, has the capacity to assist the comprehension of fundamental categories of judgements and concepts regarding how the world operates. It is the summation of all penetrations that inform the emergence of the Absolute Spirit. Subrata Mukherjee and Sushila Ramaswamy $(1999,249)$ point out that, for Hegel, "separateness had to be ended by a theory of unity of totality within the ambit of reason." This principle, Hegel pursued in his Phenomenology of Spirit, wherein he discusses how consciousness travels from the most primitive stages into the highest stage, the Absolute Spirit. Specifically, Hegel explains how the principle works thus:

The logical has in point of form three sides ... These three sides do not constitute three parts of the Logic, but are moments of each logical reality, that is, of each concept ... a) Thought, as the Understanding, sticks to finite determinacies and their distinctness from one another ... b) 
The dialectical moment is the self-sublation of such finite determinations and their transition into their opposites ... c) The speculative moment, or that of positive Reason, apprehends the unity of the determinations in their opposition - the affirmation that is contained in their dissolution and transition (HEGEL 1969, 31).

In the foregoing excerpt, Hegel discusses how a thesis and antithesis clash and lose their individual identities in a third value synthesis. This synthesis, in turn, evolves into a thesis awaiting another anti-thesis. The process continues ad infinitum. In order to have a good grasp of how this works, consider the scenario: "For proposition or concept $A$ there is a negation, not- $A$; and within the two there is a synthetic unity, or synthesis, $B . B$, however, has a negation, not- $B$, and within $B$ and not- $B$ there is a synthesis, $C$, and so on. Thus, the higher levels of the system are implicit in the lower levels - for example, $C$ and $B$ are both implicit in $A$ " (MOORE \& BRUDER 2011, 139). What needs to be also said is that the lower levels of consciousness lose their identities in the higher levels of consciousness. This motion of consciousness continues in levels and stages ad infinitum (see Diagram 1 below for details). Hegel puts this better: "Consciousness must now grope forward to an understanding of objects in the form of self. But it does so by gradual stages, and directs itself into a number of distinct mental postures in which separate sides of the object are gradually brought together" (HEGEL 1977, 530). This is an underlying outlook or position that he applies to nearly all his intellectual endeavours from logic to metaphysics and history.

Hegel's principle of dialectics underscores determinism. In one of his works, he states, "in the pure light of this divine Idea...the illusion that the world is a mad or foolish happening disappears" (HEGEL 1977, 89). Idea or Spirit determines the course of events in the physical phenomenon, obeying the laws of dialectics. On this note, he expatiates:

Spirit does not toss itself about in the external play of chance occurrences; on the contrary, it is that which 
Arụmarụka: Journal of Conversational Thinking

determines history absolutely, and it stands firm against the chance occurrences which it dominates and exploits for its own purpose (HEGEL 1977, 89).

Anti-Thesis

Thesis
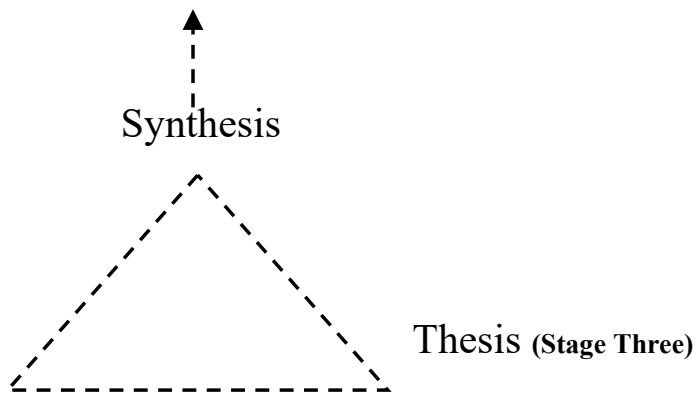

Synthesis

Upward motion ad infinitum

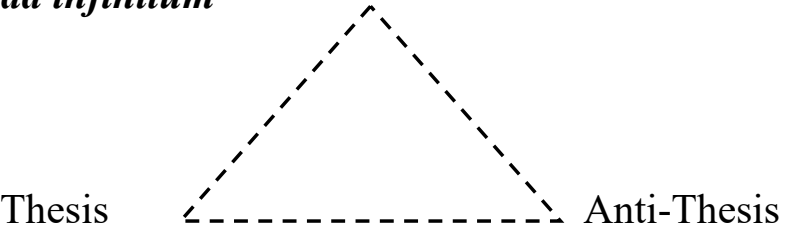

(Stage Two)
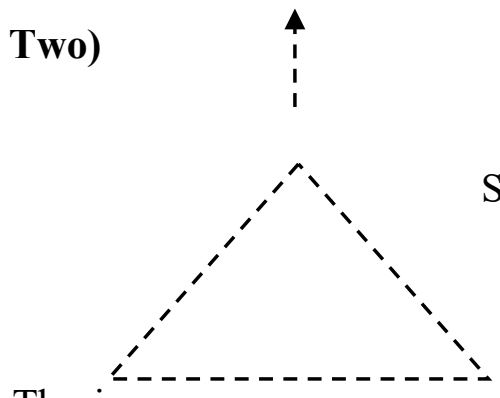

Synthesis

Thesis

Anti-Thesis

(Stage One:

lowest level)

(Diagram 1 signifying the movement of consciousness from lower to higher levels) 
Hence, all changes in the universe may be discerned as the activity of the Absolute Spirit externalising itself in the material phenomena. In other words, "the Absolute Spirit externalises itself in and through the material universe. This implies that all changes that occur in the universe are traced to the Absolute Spirit" (UKACHUKWU 2019, $6)$.

With the inner kernel of Hegel's dialectics unearthed, it is clear that in a synthesis, the thesis and anti-thesis lose their independent identities. The two become one, which in turn encounters another opposite entity. This dialectical process continues in Hegel's system. Whereas several criticisms or objections have been levelled at Hegel's dialectics, and several versions of dialectics have sufficed. These are however beyond the scope of the present study. My chief aim is to react to the tandem that critics of Ezumezu logic find with Hegel's dialectics. In the section that follows, I turn my attention to Ezumezu logic.

\section{The Character of the Third Value 'e' Ezumezu Logic}

In this study, I do not boast to have the capacity to fully detail Ezumezu logic. Other publications ${ }^{1}$ have already concerned and even applied the logic to African metaphysics, process metaphysics, African ontology and a host of other pressing issues in Africa and beyond. My contention in the present piece however is to extrapolate the place of the third value, ' $\mathrm{e}$ ' in the logic system and to make its character as vivid as possible in order to eradicate its conflation with Hegel's synthesis. In the course of this exposition, I will mention some pertinent aspects of the logic that will aid the reader's understanding concerning how the logic system functions.

Ezumezu is an Igbo concept which means aggregation. It fits as a philosophy of logic, methodology, and a formal system. Ezumezu logic is a method for original African thinking that thrives on "the principle of nmeko or relationship and is grounded in a truth-

\footnotetext{
${ }^{1}$ For publications that have disclosed and applied, comprehensively, the deep character of Ezumezu logic, see CHIMAKONAM 2019; OFUASIA 2019; CHIMAKONAM \& OGBONNAYA 2021 to name a few.
} 
glut-compliant system of three-valued logic" (CHIMAKONAM \& OGBONNAYA 2021, 4-5). For Chimakonam (2019, 96), "Ezumezu as a prototype of African logic studies values, meanings and understanding of logical language. Nothing is treated without content. It is both an art and science which studies the logical relationship among realities expressed in terms of propositions and symbols. Ezumezu, therefore, is a logical framework that can be used to explain and analyse experiences in African world-view." Compared to the dominant bivalent system of Western logic, Ezumezu is trivalent since it "consists of three values namely; truth (ezu), falsity (izu) and ezumezu with small letter 'e' (complemented). A system of logic is trivalent if it has three values. This is opposed to bivalence in which a system of logic boasts of two values namely: truth and falsity" (CHIMAKONAM 2019, 98).

Much as ' $\mathrm{T}$ ' and ' $\mathrm{F}$ ' are treated as contradictories in Western thought, Chimakonam (2019) proposes that they are sub-contraries in African thought. In a recent publication, it was explained that "In Ezumezu logic, for example, seemingly opposed variables are not read as contradictories but as subcontraries making it not only possible but necessary for variables to engage in a productive relationship" (CHIMAKONAM \& OGBONNAYA 2021, 3). It is important to stress that Ezumezu logic is not the first trivalent logic. According to Chimakonam $(2019,160)$, it is "a variant of threevalued logic that is context-dependent, which, unlike the variants by Jan Lukasiewicz and Stephen Kleene, prioritises complementarity rather than contradiction."

When two seemingly opposed variables, ${ }^{2}$ ' $\mathrm{T}$ ' and ' $\mathrm{F}$ ', encounter each other, Ezumezu logic calls for a third value which is not a synthesis of these individual variables. This third value is a complement where the two seemingly opposed variables do not lose their identities. This third value is "both true and false (truth-glut), rather than neither true nor false (truth-gap) or either true or false (determinism). The complementing variables assume strict values of true or false when they depart the complementary mode and return to what is called the contextual mode" (CHIMAKONAM \&

\footnotetext{
${ }^{2}$ This could mean variables that belong to different ontological categories.
} 
OGBONNAYA 2021, 6). In this system of logic, propositions are evaluated on the basis of their being necessary, impossible or the complement of both seemingly opposed variables.

Two types of reasoning occur in the third value: notional solidarity and creative struggle. In notional solidarity, two similar variables are involved, whereas, in the case of creative struggle, two seemingly opposed variables are involved. "It is the latter type of relationship," according to Chimakonam \& Ogbonnaya (2021: 3), "that yields new ideas." It is the process of creative struggle that Chimakonam then gives more attention to. Synthesis is an anathema, hence, there is both a conjunction and disjunction motion in the exchange between the two seemingly opposed variables enmeshed in creative struggle. As the system is quick to be passed as the African version of Hegel's dialectics, Chimakonam \& Ogbonnaya (2021, 5) debunk this assumption thus:

We show that any attempt that presents the relationship of seemingly opposed variables in the African systems of thought as a Hegelian-style dialectics that yields a synthesis is mistaken. The conjunctive motion that leads to the relationships of notional solidarity and creative struggle, is temporal and is interrupted now and then by 'tension of incommensurables.' It ultimately terminates at 'benoke point' that prevents a synthesis.

For the logic which mediates interaction in conversational thinking, the 'benoke point' is the maximum place where two seemingly opposed variables interact and retain their individual identities, whereas the 'tension of incommensurables' is the minimum place of interaction. It signals the breakdown of conversation. If the tension of incommensurables is surmounted, then there is a conjunctive and disjunctive interchange between the two discussants from whence new vistas to knowing are attained. More so, it must be stated that the series of conjunction and disjunction motions between ' $\mathrm{T}$ ' and ' $\mathrm{F}$ ' are set between the two extremes - Benoke point and tension of incommensurables (see Diagram 2 below). 
Arụmarụka: Journal of Conversational Thinking

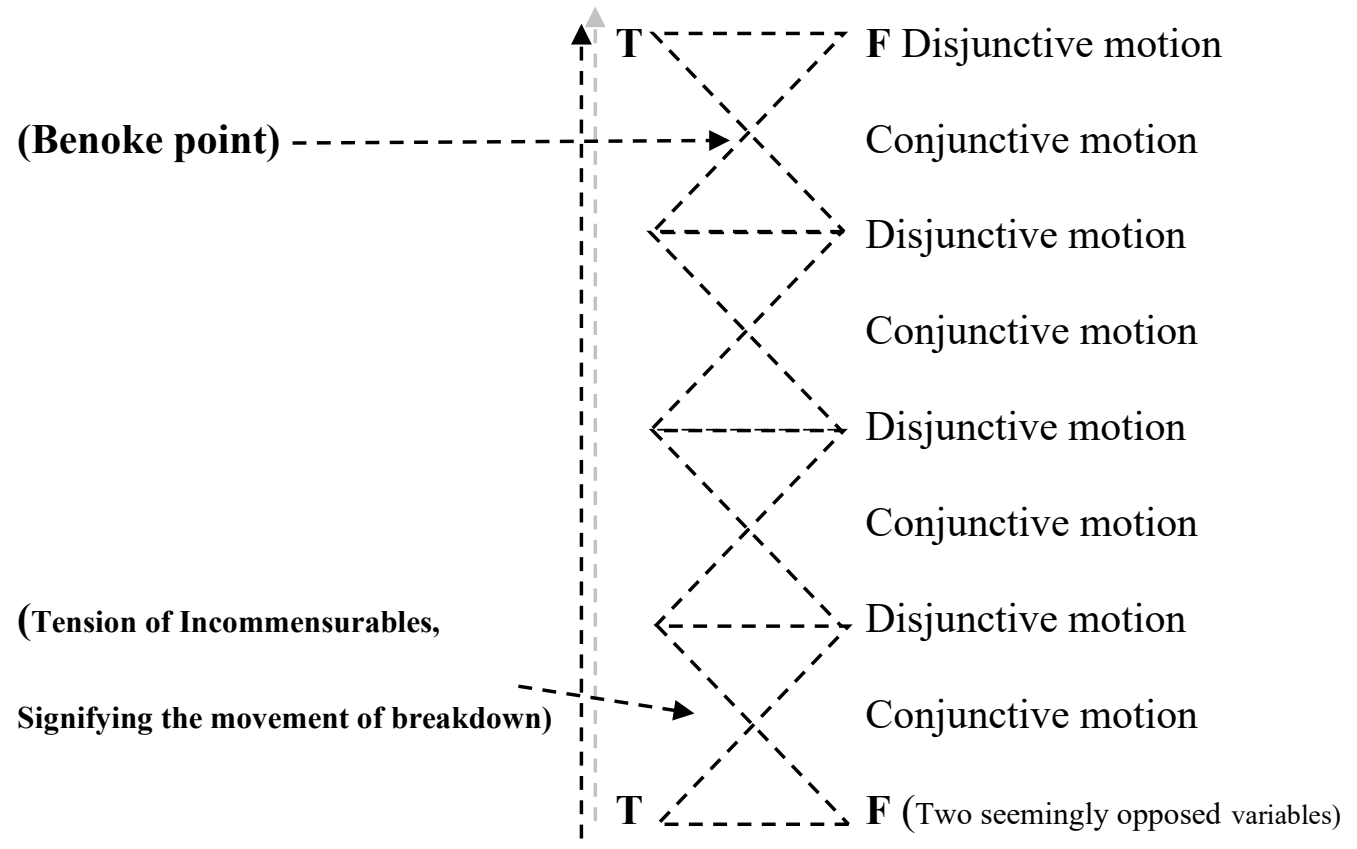

(Diagram 2 signifying "Creative Struggle" in Ezumezu

third value) 
The entire process of creative struggle takes cognizance of the supplementary laws and the arumaristic and ohakaristic modes of inferences, paying attention to contexts (see CHIMAKONAM 2019). While explaining this logical relationship or modes of inferences in Ezumezu logic, Chimakonam (2019, 117) maintains:

Arumaristics is when the peripheries move towards the centre for a logical relationship of inclusion in the complementary mode marshalled by the law of onona-etiti, and ohakaristics is when the centre moves towards the peripheries for the logical relationships of integration and complementation to occur between the peripheries from their contextual modes.

In addition to the foregoing, Ezumezu admits the traditional laws of thought: contradiction, identity and excluded-middle but adds another three laws that bring the total it employs to six (see CHIMAKONAM 2019, 96). These three supplementary laws are: Njikoka, Nmekoko, and Onana-etiti.

The law of njikoka states that " $\mathrm{A}$ is true if and only if $\mathrm{A}$ is true wedge-implies A and B is true. Here, the variable A is said to be true only in the company of another or other variables, not in isolation" (CHIMAKONAM 2019, 139). This may be represented thus:

$$
(\mathrm{T}) \mathrm{A} \uparrow(\mathrm{T}) \mathrm{A} \mid \rightarrow(\mathrm{T})(\mathrm{A} \wedge \mathrm{B})
$$

The law of nmekoka states that ' $\mathrm{C}$ ' is or equals a complement of ' $\mathrm{T}$ ' and ' $\mathrm{F}$.' This ' $\mathrm{C}$ ' is the third truth value called ezumezu or $n w a-$ izugbe. The supplementary law of nmekoka is represented in symbolic logic thus:

$$
(\mathrm{T} \mid \supset \mathrm{F})=\mathrm{C}
$$

Onana-etiti, the third supplementary law employs a conjunction where Aristotle's law of excluded middle involves a disjunction, so it may read as an inclusive middle. This is one of the most striking features of Ezumezu which allows its applicability and relevance in process ontology and African ontology (OFUASIA 2019). The law 
states that "A could be both true and false or if a thing is equal to itself it can be unequal to or different from itself depending on context" (CHIMAKONAM 2019, 140). Onana-etiti may be represented thus:

$$
\text { (T) } \mathrm{A} \wedge(\mathrm{T}) \sim \mathrm{A} \text { or }(\mathrm{T}) \mathrm{A} \wedge(\mathrm{F})
$$

It is important to understand that whereas Njikoka hints at individual identities within the group, Nmekoka lays emphasis on group power or identity through the convergence of individual elements.

Aside the supplementary laws, Ezumezu also boasts of two theses concerning how realities are treated: the ontological and logical. The ontological thesis, on the one hand, affirms that realities persist both as independent units and as entities that are capable of converging, initiating a status quo of interdependent relationships. The logical thesis, on the other hand, maintains that values are to be given to propositions, not on the basis of facts but on the basis of contexts (CHIMAKONAM 2019, 141-2). Much as Chimakonam agrees with Gottlob Frege's (1960, xxii) proclamation: "Never to ask for the meaning of a word in isolation, but only in the context of a proposition," he insists that meaning-making is determined not by the context of appearance propositions but by the context where the propositions are uttered. In other words, for Frege (1960), the sense or thought signified by a proposition is a determinant of truth-value. Chimakonam (2019), on the other hand, maintains that truth-values are not sought in the thought that are expressed by propositions but within the circumstances where these propositions are pronounced or uttered.

Through these supplementary laws of thought, one finds a logic that not only grounds theories in African philosophy but is also applicable even in process metaphysics too. This is because African ontologies, like process metaphysics, violate Aristotle's law of contradiction and excluded middle in some contexts. As a result, each of these systems has not been given the proper attention it deserves. With Ezumezu, this seeming violation is now regarded as normal since "in loosening the laws of excluded middle and contradiction on the one hand and identity on the other..., I mitigated the characters of absolute difference and absolute identity 
thereby shaded determinism from bivalence and transformed the latter into trivalence (CHIMAKONAM 2019, 97).

Having been able to discuss albeit tersely, the main thrust of Ezumezu logic, it is now important to draw the departures with Hegel's dialectical logic. Unless this distinction is carried and made vivid, it is the case that the conflation and confusions that emanates from critics may continue to hold sway. This is the thrust of the section that follows.

\section{The Third Value, ' $e$ ' in Ezumezu Logic and the Notion of Synthesis in Hegel's Dialectics}

In the preliminary sections of this work, I have laboured to unveil the underlying traits

of Hegel's dialectics and Chimakonam's Ezumezu logic, focusing on the third value in each system? Perhaps the differences in each of the systems I had dedicated two sections to, are still unclear, I will use the present section in articulating the differences, which makes any effort to brand them as synonymous futile.

In the first place, the third value in Hegel's dialectics, synthesis, as the name implies, coalesces two independent realities into one. As Peter Hanks $(1976,1591)$ notes, synthesis means "the combination of parts or elements, as material substances or objects of thought, into a complex whole." He further states that it is a system that is redolent in Hegel's system wherein contradictory judgments unite to form a higher truth (HANKS 1976, 1591). Elsewhere, synthesis is defined as "an exposition assembling the various parts into a whole" (CAYNE 1992, 1004). When the definitions of these lexicographers are taken along with the diagram and discussion on Hegel's dialectics, what is deducible is that the third value, synthesis, swallows the individual contradictory elements that converge. What makes Hegel's dialectics more comprehensive than the definition offered by these lexicographers is that the synthesis inescapably evolves into a new thesis. This new thesis is, however, stronger and more ample vis-à-vis the hitherto two contradictory variables. Later on, it encounters an even more forceful and comprehensive anti-thesis. This commands both new 
thesis and anti-thesis to lose their individual values for a comprehensive synthesis. This entire process, as Hegel indicates, continues ad infinitum, as it guarantees the interaction and manifestation of Spirit with physical reality. This is the chief character of Hegel's dialectics.

The third value, 'e' in Chimakonam's Ezumezu logic, signifies the creative interaction between two seemingly opposed variables. Within this third value, the creative struggle undergirded by the motion of conjunction and disjunction occurs due to the interaction between the two seemingly opposed variables or conversants. When the two parties reach a point where there can no longer be any further motion, they retain their individual identities, and the third value signifies the product of their encounter. By retaining their individual identities, it is clear that they are not swallowed up in the third value. The third value has a 'life' of its own, distinct from each of the seemingly opposed variables that conversed.

Another important point of departure, which makes the third value in the logic of conversational thinking to differ from Hegel's dialectics, is the emphasis on contexts. Whereas Hegel's dialectics continues ad infinitum, the logic of conversational thinking involves two seemingly opposed variables within a particular context. The encounter between the variables, in Ezumezu logic, does not yield a third value which transmutes into a singular comprehensive thesis, awaiting another anti-thesis. Each of the seemingly opposed variables can still engage in conversation in other contexts. However, they are no longer the same in terms of quality, even when their quantity remains one. To make this more glaring, I make a distinction between qualitative and quantitative motion and reinforcement.

On the one hand, by qualitative motion and reinforcement, I refer to a status quo in which a variable or entity has moved from a region of lower consciousness or knowledge into a higher level. On the other hand, by quantitative motion and reinforcement, I mean a variable or entity that has evolved from its own essence into another. Here, it is either one becomes two or more or one is 'lost in the 
crowd.' The former depicts the logic of conversational thinking, whereas Hegel's dialectics illustrates the latter.

In the logic of conversational thinking, the aftermath of the motions and encounter between two seemingly opposed variables, strengthen or reinforce each of them (improved quality). Quantity is, however, out of the picture, since their identities are neither lost or compromised in a complex whole nor increased into two or more.

In Hegel's dialectics, quantitative and qualitative motion and reinforcement are rife. The identities of thesis and anti-thesis transfigure into a synthesis. This synthesis commands motion and strength both in the qualitative and quantitative sense. However, the fusion of the two independent variables into a synthesis signifies a motion from two into one. Furthermore, this new synthesis, the one variable, is a qualitatively reinforced entity that soon transmutes into a stand-alone thesis, which has swallowed previous individual opposing or contradicting judgments.

I must end this section by rehashing once more that in Ezumezu, the logic that pilots thought and theory in conversational thinking, seemingly opposed variables are perceived as subcontraries. This is, however, not the case in Hegel's dialectics in which, all theses and anti-theses are situated within the ambience of contradiction.

\section{Conclusion}

The tendency to equate the logic of conversational thinking with Hegel's dialectics has been the main concern of this disquisition. With this piece, I have been able to make the distinction as vivid as I can. I, therefore, enjoin critics and those who take a prejudiced stance to, following my exposition, return and engage the text more closely and see if it is able to assist or make reality intelligible. The task to birth an original idea for the benefit of humanity is not limited or gifted to an individual or a group. The logic of conversational thinking needs to be engaged fairly to discern where it is flawed and hopefully be revised and reinforced in order to reflect Africa's contribution to the world. Unless this is done, the African intellect will continue to be passed as subaltern and also be 
on the intellectual defensive, seeking to prove itself without getting the attention and progress needed.

\section{Relevant Literature}

1. ATTOE, Aribiah David \& AZEEZ, Abiola. "Afrophobia in Africa: A Conversational Response," [African Philosophy: Whose Past and Which Modernity? S.L. Oladipupo Ed.], pp351364, 2021. Obafemi Awolowo University Press: Ile-Ife. Paperback

2. BEISER, F. (ed). [The Cambridge Companion to Hegel], 1993. Cambridge University Press: Cambridge. E-Book.

3. CAYNE, Bernard S. [The New Webster Dictionary of the English Language], 1992. Lexicon: New York. Paperback.

4. CHIMAKONAM, Jonathan O. \& OGBONNAYA, Uchenna L. [African Metaphysics, Epistemology and a New Logic: A Decolonial Approach to Philosophy], 2021. Springer Nature: Cham, Switzerland. E-Book.

5. CHIMAKONAM, Jonathan O. [Ezumezu: A System of Logic for African Philosophy and Studies], 2019. Springer Nature: Cham, Switzerland. E-Book.

6. FREGE, Gottlob. [The Foundations of Arithmetic: A Logicomathematical Inquiry into the Concept of Number], 1960. Harper Torch Books: E-Book.

7. HANKS, Peter. [Encyclopaedic World Dictionary], 1976. The Hamlyn Publishing Group Limited: London. Paperback.

8. HEGEL, George Wilhelm Friedrich. [Phenomenology of the Spirit], 1977. Clarendon Press: Oxford. E-Book.

9. HEGEL, George Wilhelm Friedrich. [Science of Logic], 1969. Allen \& Unwin: London. Paperback.

10. KENNY, Anthony. [An Illustrated Brief History of Western Philosophy], 2006. Blackwell Publishing Ltd: New York. EBook.

11. MARTENS, David. "Some conservatisms in African Logic." [Paper Presented at The Third Biennial African Philosophy World Conference. University of Dar es Salaam, Tanzania. $28^{\text {th }}$ $31^{\text {st }}$ October, 2019], Unpublished. 
12. MARX, Karl. [Capital: A Critique of Political Economy], 1906. Modern Library: New York. E-Book.

13. MOORE, Brooke N. \& BRUDER, Kenneth. [Philosophy: The Power of Ideas], 2011. McGraw Hill: New York. E-Book.

14. MUKHERJEE, Subrata \& RAMASWAMY, Sushila. [A History of Political Thought: Plato to Marx], 1999. Prentice-Hall of India Private Limited: New Delhi. Paperback.

15. OFUASIA, Emmanuel. "Ezumezu: A System of Logic for African Philosophy and Studies," [International Journal of African Renaissance Studies - Multi-, Inter- and Transdisciplinarity], pp242-245, 2021. Vol 16. No1. Web.

16. OFUASIA, Emmanuel. "Unveiling Ezumezu Logic as a framework for Process Ontology and Yorùbá Ontology," [Filosofia Theoretica: Journal of African Philosophy, Culture and Religions], pp63-84, 2019. Vol 8. No. 2. Web

17. OGBONNAYA, Lucky U. "How African is Three-Valued Logic? A Conversation with the Three-Valued Logic Traditions in Africa," [African Philosophy: Whose Past and Which Modernity? S.L. Oladipupo Ed.], pp213-230, 2021. Obafemi Awolowo University Press: Ile-Ife. Paperback

18. REYES, R.S.M. "Deleuze contra Hegel: The Rupture of the Dialectics towards Non-Conceptual Difference," [KRITIKE], pp119-138, 2014, Vol 8. No2. Web.

19. UKACHUKWU, Chidiebere E. "On Whitehead's Reformed Metaphysics and the Dialectics of Hegel and Marx: A Discourse on Resistance," [Philosophia: E-Journal of Philosophy and Culture], pp4-16, 2019. Vol 22. Web 